\title{
Chronic biliary colic associated with ketamine abuse
}

This article was published in the following Dove Press journal:

International Medical Case Reports Journal

2 June 2016

Number of times this article has been viewed

\section{Ahmed Al-Nowfal \\ Yahya A Al-Abed}

Department of Surgery, Southend University Hospital, Prittlewell Chase,

Westcliff-on-Sea, Essex, UK
Correspondence: Ahmed Al-Nowfal Department of Surgery, Southend University Hospital, Prittlewell Chase, Westcliff-on-Sea, Essex SSO ORY, UK

Tel +44I702435555

Email alnowfal@gmail.com
Introduction: Biliary colic is a common clinical presentation, with the majority of cases being related to gallstone disease. However, rarely, patients may present with biliary symptoms without evidence of gallbladder stones - referred to as acalculous gallstone disease. This case report details a rare case of chronic biliary colic associated with ketamine abuse.

Case presentation: A 24-year-old Caucasian female presented to the emergency department with a history of intermittent right upper quadrant pain associated with nausea and malaise. She had experienced bouts of similar symptoms three times a year for the past 4 years. Various investigations had been conducted during her multiple admissions, which showed possible dilatation of the common bile duct, with no evidence of gallstones.

Conclusion: Patients can present with a dilated common bile duct and an acalculous cholecystitis. This requires considerable investigation, with an emphasis on drug history, especially with the current rise of recreational hallucinogenic drug abuse.

Keywords: gastroenterology, hepatology, substance abuse, ketamine, acalculous gallstones, biliary disease

\section{Introduction}

Biliary colic is a common presentation in clinical practice. The majority of cases are related to gallstone disease. However, rarely, patients may present with biliary symptoms without evidence of gallbladder stones; commonly referred to as acalculous gallstone disease. Patients may present with acalculous biliary colic or cholecystitis. This has been described in association with a wide variety of clinical conditions, ${ }^{1}$ the majority being related to infections and hematological disorders (Table 1).

There have been recent reports of increasing use of ketamine for recreational purposes (street ketamine). ${ }^{2}$ Ketamine was originally developed for use in anesthesia, especially within pediatrics. Street ketamine is impure containing 30\%-90\% ketamine, the reminder being composed of cutting agents such as paracetamol, caffeine, and flour. It is sold as a liquid or white powder. It is injected, snorted, or swallowed. Ketamine has a fast-acting nature and prolonged high with a limited hangover effect, which makes it a popular nightclub drug. Ketamine abuse at moderate-to-high doses can cause sedation, immobility, and amnesia; it increases the risk of serious central nervous system and cardiovascular effects, including respiratory distress or arrest, resulting in death. ${ }^{3}$

The physical side effects of ketamine when used for ecstasy is well researched and case reports show that ketamine may be associated with chronic epigastric pain, nonobstructive biliary dilatation, abnormal liver function tests, and urinary bladder dysfunction. $^{4}$ 
Table I Risk factors for acute acalculous cholecystitis

\begin{tabular}{ll}
\hline Acute rnyelogenous leukemia & End-stage renal \\
Acquired immune deficiency syndrome & disease \\
Ampullary stenosis & Heart failure \\
Bone marrow transplantation & Hemobilia \\
& Immunosuppression \\
Burns & Infections \\
Cardiopulmonary resuscitation & Major trauma \\
Childbirth & Mechanical ventilation \\
Choledochal cyst & Medications (eg, \\
& opiates, sunitinib) \\
& Metastases to porta \\
Cholesterol emboli & hepatis \\
Coronary heart disease & Multiple transfusions \\
Cystic duct obstruction by a percutaneous & Nonbiliary surgery \\
transhepatic catheter in the bile duct & Sepsis/hypotension \\
Diabetes mellitus & \\
& Total parenteral \\
& nutrition \\
\hline
\end{tabular}

Note: This is a list of the common conditions associated with the development of acute acalculous cholecystitis. Adapted from Afdhal NH. Acalculous cholecystitis. In: Post TW, editor. UpToDate. Waltham, MA: Wolters Kluwer. Accessed October I8, 2015.'

Here, we present a case of a young Caucasian female who had a 4-year history of ketamine abuse and presented with multiple episodes of right upper quadrant (RUQ) pains and symptoms suggestive of biliary colic. Investigations showed a dilated common bile duct (CBD) with no evidence of gallstone disease.

This study was deemed exempt from full review according to the Southend University Hospital Ethical Committee, UK as this was a retrospective, non-comparative study. Written informed consent was obtained from the patient for publication of this case report and any accompanying images.

\section{Case report}

A 24-year-old Caucasian female presented to the emergency department with a history of intermittent RUQ pain associated with nausea and malaise. She reported similar episodes of her symptoms three times a year for the past 4 years. The pain was not associated with meals or posture. She did not have any significant past medical history and did not take any regular medicines. On examination, she was hemodynamically stable; there was no fever or tachycardia and her blood pressure was within normal limits. Abdominal examination showed no evidence of peritonitis but revealed tenderness in the RUQ and epigastric regions. Urine dipstick for blood and pregnancy was negative. Full blood count and serum biochemistry showed a normal white cell count of $5.8 \times 10^{9} / \mathrm{L}$ with normal renal and liver function tests. The initial differential diagnoses by the admitting causality officer included biliary colic and peptic ulcer disease. She was admitted and started on opiate analgesics and antispasmodics and her symptoms gradually improved. Ultrasound scan of the abdomen demonstrated a normal liver and gallbladder with no evidence of gallstones but with a dilated CBD of $8.5 \mathrm{~mm}$. Two days following admission, she underwent magnetic resonance cholangiopancreaticography, which again showed no gallstones, but also conversely no evidence of intra- or extrahepatic biliary dilatation with a CBD of normal diameter.

On review of our patient's previous hospital admissions, we noted that 60 days prior, she had presented with similar episodes of RUQ pain; ultrasound scan of the abdomen and an esophagogastroduodenoscopy were normal. Two years prior to that, she had presented to a different unit with similar symptoms and at the time radiological investigations revealed a dilated CBD of $11 \mathrm{~mm}$ with no other abnormality.

On further enquiry into her social history, the patient admitted recreational use of oral ketamine over the past 4 years, all episodes of which coincided with her intermittent abdominal symptoms. She denied the use of any other illicit drugs and only moderately consumes alcohol.

\section{Discussion}

Ketamine is an $N$-methyl-D-aspartate receptor antagonist developed in 1962 for use in anesthesia. ${ }^{5}$ However, "street ketamine," which is a close analog of ketamine, has become a commonly used drug for ecstasy. Unlike the other well-known dissociative illicit drugs, ketamine is very short-acting. It takes effect within about 10 minutes, while its hallucinogenic effects last up to 2 hours when ingested orally, making it a popular "club drug" often used by teens and young adults at dance "rave" parties. ${ }^{6}$

Ketamine is metabolized by hepatic microsomal enzymes and has a half-life of 2.5 hours. It is excreted mainly through urine $(90 \%)$, with the remainder through bile. ${ }^{7}$

Wide variety of symptoms is associated with ketamine abuse. A large number of abusers present with impaired level of consciousness, dizziness, abdominal pain, and lower urinary tract symptoms. The most common physical signs in patients with ketamine abuse are hypertension, tachycardia, and abdominal tenderness. ${ }^{8}$

Severe urinary bladder dysfunction and recurrent episodes of epigastric pain associated with dilated CBD in the absence of gallstones in ketamine abusers has also been reported. ${ }^{7}$

A study by $\mathrm{Ng}$ et $\mathrm{al}^{8}$ investigated the clinical presentations of ketamine abusers in 233 cases. Abdominal pain was the presenting complaint in $21 \%$ of cases while abdominal tenderness was noted in $18 \%$ of patients. Two out of 35 patients 
who had radiological investigations had confirmed dilated bile ducts in the absence of gallstone disease. ${ }^{9} \mathrm{~A}$ case series published by Wong et $\mathrm{a}^{10}$ also presented similar findings.

In our case radiological investigations failed to identify a cause for a dilated CBD. Based on previous studies and case series, we believe that the ketamine abuse is the most likely cause for this. Although the exact pathophysiology of ketamine-induced dilated biliary system is unknown, it is postulated that ketamine increases the flow of resistance across the sphincter of Oddi. ${ }^{11}$

In conclusion, this case report highlights the importance of drug history taking in patients presenting with abdominal pain and specifically biliary colic.

\section{Acknowledgment}

We would like to thank all the NHS staff who tirelessly look after their patients in these difficult times. No funding was provided to write this case report.

\section{Disclosure}

The authors report no conflicts of interest in this work.

\section{References}

1. Afdhal NH. Acalculous cholecystitis. In: Post TW, editor. UpToDate. Waltham, MA: Wolters Kluwer. Accessed October 18, 2015.
2. Adam R Winstock. The Global Drug Survey 2014 findings. Available from: http://www.globaldrugsurvey.com/facts-figures/the-global-drugsurvey-2014-findings. Accessed October 18, 2015.

3. National Institute on Drug Abuse. Hallucinogens and dissociative drugs. Available from: http://www.drugabuse.gov/publications/researchreports/hallucinogens-dissociative-drugs/what-are-effects-commondissociative-drugs-brain-body. Accessed October 18, 2015.

4. Wood D, Cottrell A, Baker SC, et al. Recreational ketamine: from pleasure to pain. BJU Int. 2011;107(12):1881-1884.

5. Jansen, KL. A review of the nonmedical use of ketamine: use, users and consequences. J Psychoactive Drugs. 2000;32:419-433.

6. Anderson L. Ketamine. Available from: http://www.drugs.com/illicit/ ketamine.html. Accessed October 18, 2015.

7. Adamowicz P, Kala M. Urinary excretion rates of ketamine and norketamine following therapeutic ketamine administration: method and detection window considerations. J Anal Toxicol. 2005;29(5): 376-382.

8. Ng SH, Tse ML, Ng HW, Lau FL. Emergency department presentation of ketamine abusers in Hong Kong: a review of 233 cases. Hong Kong Med J. 2010;16(1):6-11.

9. Lo RS, Krishnamoorthy R, Freeman JG, Austin AS. Cholestasis and biliary dilatation associated with chronic ketamine abuse: a case series. Singapore Med J. 2011;52(3):e52-e55.

10. Wong SW, Lee KF, Wong J, Ng WW, Cheung YS, Lai PB. Dilated common bile ducts mimicking choledochal cysts in ketamine abusers. Hong Kong Med J. 2009;15(1):53-56.

11. Thune A, Jivegård L, Polland H, Moreau J, Schwartz JC, Svanvik J. Location of enkephalinase and functional effects of [Leu 5]enkephalin and inhibition of enkephalinase in the feline main pancreatic and bile duct sphincters. Clin Sci (Lond). 1992;82:169-173.
International Medical Case Reports Journal

\section{Publish your work in this journal}

The International Medical Case Reports Journal is an international, peer-reviewed open-access journal publishing original case reports from all medical specialties. Previously unpublished medical posters are also accepted relating to any area of clinical or preclinical science. Submissions should not normally exceed 2,000 words or

\section{Dovepress}

4 published pages including figures, diagrams and references. The manuscript management system is completely online and includes a very quick and fair peer-review system, which is all easy to use. Visit $\mathrm{http}: / /$ www.dovepress.com/testimonials.php to read real quotes from published authors. 